APPENDIX 2: CATALOGUE OF ILLUSTRATED COARSE POTTERY VESSELS

\section{A.2.1 Amphorae}

- 1. DPS99, Unstrat, 'Service trench' (Illus 13:1) Fabric A01. A single sherd representing approximately $20 \%$ of the rim. A similar form at Augst was found in contexts dated AD 70-110 (Martin-Kilcher 1987: no. 534).

\section{- 2. DPS99, Context 010, upper fill of Pit 011 (Illus 13:2)}

Fabric A01. Two joining sherds representing approximately $20 \%$ of the rim. Close parallels to this form in Martin-Kilcher's scheme occur in the period AD 70-110 (Beilage D, nos 64-71). A similar form of Dressel 20 rim has been found at the nearby legionary fortress of Inchtuthil, which was probably occupied from AD 83-86 (Darling 1985, no. 72).

\section{A.2.2 Flagon}

\section{- 3. DPSE07, Context 004, topsoil (Illus 13:3)}

Fabric O06. A rimsherd and three chips from a ringnecked flagon with a fairly straight, vertical neck. Lid?

\section{-4. DPS99, Context 007, base of oven $\mathrm{C002}$ (Illus 13:4)}

Fabric F01. A brown colour-coated bead-rimmed lid(?). M Darling and B Precious (pers comm) suggest that this is a Pompeian Redware 3 lid from Central Gaul. There are sherds from 10 vessels, including a lid, from Inchtuthil (Darling 1985: nos 67-71).

\section{A.2.3 Mortaria}

\section{- 5. DPS99, Context 007, base of oven $\mathrm{C002}$ (Illus 13:5)}

Fabric M01. An oxidised mortarium with bead set well below flange. The fabric, together with the provenance, date and form, indicate manufacture in Scotland. We know little about the production of mortaria in 1st century Scotland except at Inchtuthil and Elginhaugh, but there is no doubt that it occurred. There is no parallel for this form in this period, but fortunately the context leaves no doubt of its Flavian date. Nevertheless, the form, given the fabric and context, fits well with Neronian-Flavian production in a military workshop not far from Doune. Variety of rim-profile, often unusual, and unusual fabric is, in fact, characteristic of mortaria made by the army in Britain, in the pre-Flavian and early Flavian periods. The workshops involved were small and served very local markets (eg Longthorpe, Metchley, Trent Vale, Exeter, Wroxeter, Usk, Inchtuthil and Elginhaugh).

\section{- 6. DPS99, Context 008, rake-out from ovens} (Illus 13:6)

Fabric M02. A Claudio-Neronian mortarium rim, AD 40-60, cf Strageath (Frere \& Hartley 1989: no. 1). Other examples of these vessels occurring as heirlooms are known from Strageath, Camelon (Frere \& Hartley 1989: no. 1), Binchester (Evans \& Rátkai 2010: type M091.1), and York (Monaghan 1997: no. 3406).

\section{-7. DPS99, Context 008, rake-out from ovens} (Illus 13:7)

Fabric M02. A Gillam (1970) type 238 mortarium rim, from Noyon, Oise, AD 70-100.

\section{- 8. DPS99, Context 060, upper fill of Pit 061} (Illus 13:8)

Fabric M03. A Verulamium region ware mortarium with evenly curving, down-pointing flange (incomplete). AD 60-90.

\section{-9. DPS99, Context 001, Unstrat (Illus 13:9)}

Fabric M03. A burnt Verulamium region ware mortarium with evenly curving down-pointing flange. AD 60-90.

\section{A.2.4 Bowls}

- 10. DPS99, Context 060, upper fill of Pit 061 (Illus 13:10)

Fabric M04. A segmental bowl flange/or a mortarium flange. The form of the flange fragment and the fact that it becomes thinner at the point where it meets the normal bead would better fit a segmental bowl than a mortarium. There are, however, a very few mortaria which could be cited as parallels, notably an unpublished mortarium, stamped by one of the Sexti Valerii who worked at Colchester in the 1 st century. The slight distal bead and the fabric would certainly fit with its 

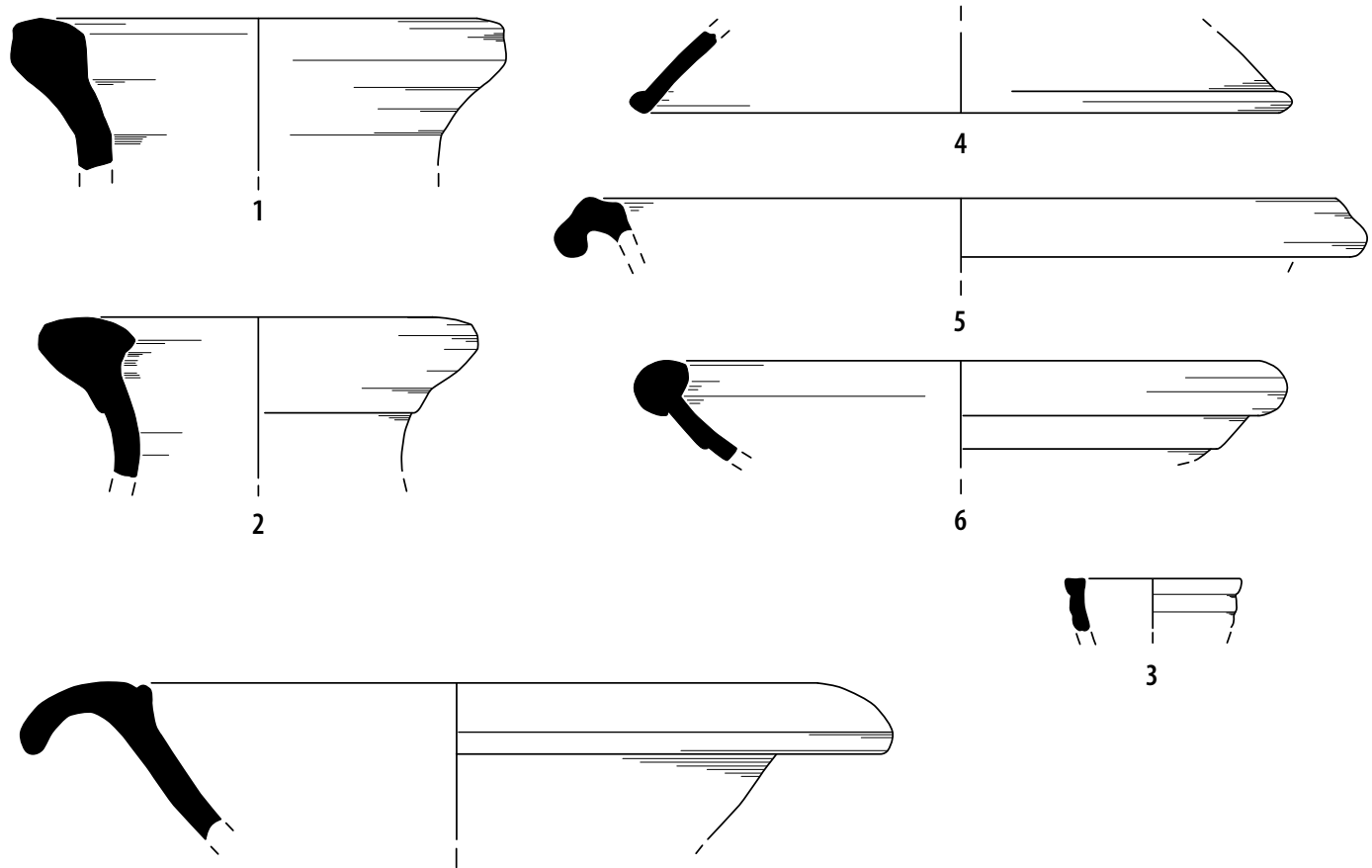

7
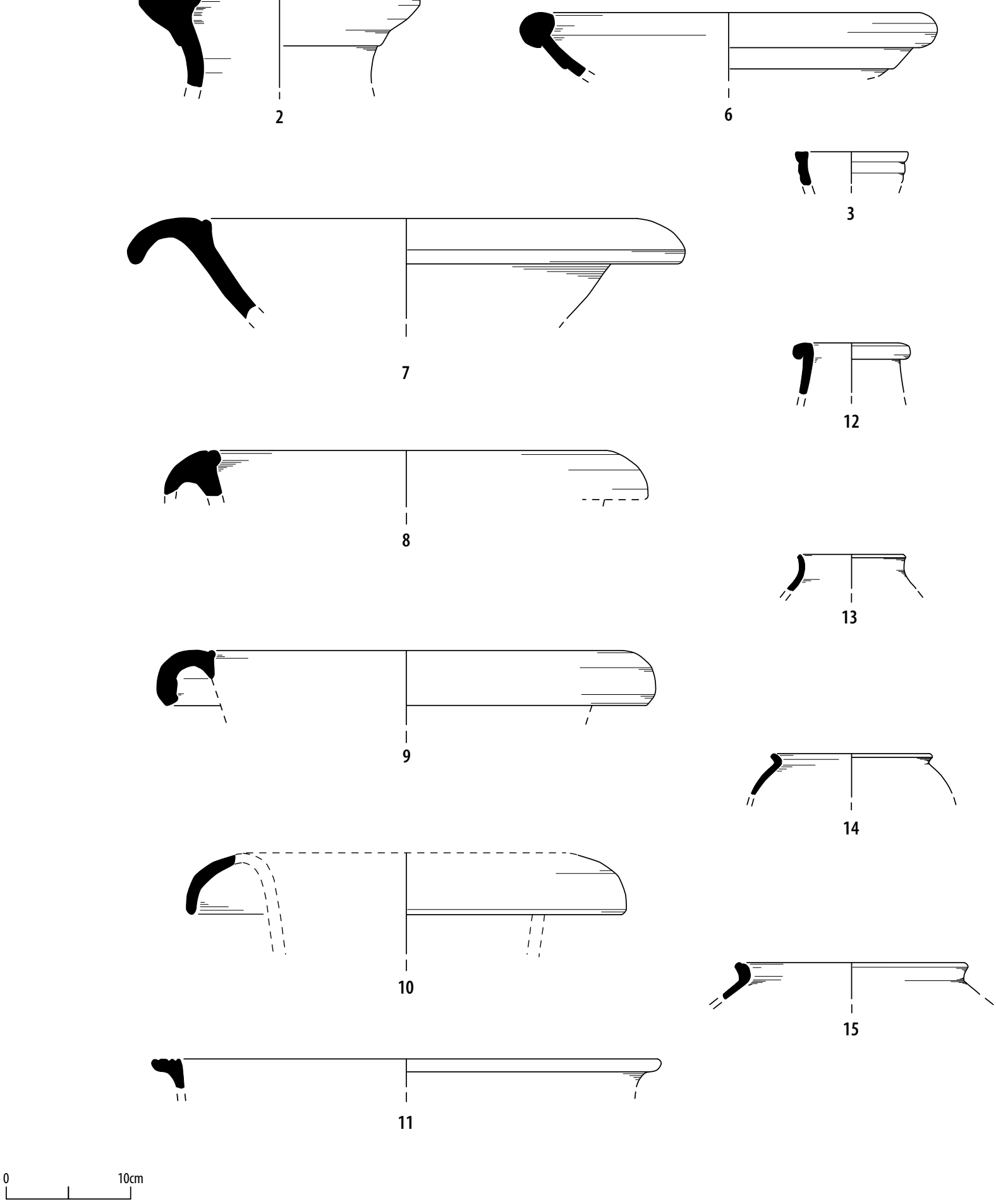

Illus 13 Pottery from 1999 and 2008 excavations. (C Headland Archaeology (UK) Ltd 
being a mortarium, but the form is exceptional for a mortarium, wherever it was made. The fabric would fit best with production at some such centre as the Aoste (Isère), but there is, as yet, no parallel there for this form. A date of AD 55-85 is indicated by the form and the similarity to mortaria made by one of the Sexti Valerii (Hartley 1999: 203, die as S110-111).

- 11. DPS99, Context 060, upper fill of Pit 061 (Illus 13:11)

Fabric O01. A reeded-rimmed bowl rim fragment, cf Inchtuthil (Darling 1985: no. 50), Flavian-Trajanic.

\section{A.2.5 Jars}

- 12. DPS99, Context evaluation 014, pit fill (Illus 13:12)

Fabric O01. A constricted-necked jar with a beaded, undercut rim, perhaps cf Strageath (Anderson 1989: no. 53).

- 13. DPS99, Context 004, fill of Pit 005 (Illus 13:13)

Fabric R01. A small jar with everted, rising rim.

- 14. DPS99, Context 010, upper fill of Pit 011 (Illus 13:14)

Fabric R01. A small globular jar, with short, everted rim, cf Inchtuthil (Darling 1985: nos 7-11), and Strageath (Anderson 1989: nos 39-45), Flavian.

-15. DPS99, Context evaluation 005, intervallum road make-up (Illus 13:15)

Fabric R05. A jar with a short, fairly vertical, grooved rim and globular form, cf Strageath (Anderson 1989: no. 50) and Inchtuthil (Darling 1985: nos 7-9), Flavian. 